\title{
Selecting and Adapting Methods for Analysis and Design in Value-Sensitive Digital Social Innovation Projects: Toward Design Principles
}

\author{
Larissa Gebken \\ University of Hamburg \\ larissa.gebken@uni-hamburg.de
}

\author{
Paul Drews \\ Leuphana University of Lüneburg \\ paul.drews@leuphana.de
}

\author{
Ingrid Schirmer \\ University of Hamburg \\ ingrid.schirmer@uni-hamburg.de
}

\begin{abstract}
Digital Social Innovations (DSI) aim to address social challenges, such as poverty and inequality, with information and communication technologies. The development of such innovations requires a broad understanding of the DSI ecosystem and the pluralistic values of the involved actors to enable sustainable development and long-term anchoring. In valuesensitive DSI projects, actors need to combine methods from DSI and Value Sensitive Design (VSD) with methods applied by the IS community for developing digital services. In this article, we address the challenge of selecting, adapting and combining methods in DSI projects. Based on the reflection of an action design research project related to the development of a digital donation system for homeless neighbors and a literature analysis, we developed design principles (DP) for the selection and adaptation of methods for supporting value-sensitive DSI projects.
\end{abstract}

\section{Introduction}

Several major societal challenges can be tied to knowledge and methods that have been developed by the IS community [1]. Knowledge from the IS field can be used to address societal challenges such as fighting poverty and inequality, strengthening justice and human rights, as well as gender equality or facing environmental and climate issues [2]. Information and communication technologies from the field of Digital Social Innovation (DSI) can address these societal issues [3] and contribute to societal change. Furthermore, a variety of (user-centered) methods to design and implement the DSI are available from the IS field. The selection and adaptation of these methods ${ }^{1}$ remains challenging due to the high number and interrelatedness of the methods [4]. Many of the methods are available for DSI projects have either been developed specifically for DSI or stem from other areas and have been adapted for use in DSI [5]. DSIs are often large in scope and scale [6], as they seek to address societal challenges $[5,6]$. Given this, a DSI very often emerges from a complex ecosystem with multiple stakeholders, whereby the DSI's potential is maximized through a transformation of the ecosystem [7]. However, the involvement of different actors within such an ecosystem can create additional challenges. Due to the pluralistic values of various actors, orientation toward a common DSI goal is difficult and has the potential to fail if there is no common understanding [8]. Moreover, despite shareholders' common desire for positive societal change, a lack of consideration of potential negative side effects and consequences of technologies can lead to negative outcomes [9].

A theory that enables DSI initiatives to align their innovation with values is Value Sensitive Design (VSD) $[10,11]$. Values are the core of VSD and they are defined as "what is important to people in their lives, with a focus on ethics and morality" [12]. A variety of methods is employed to perform value election, representation and analysis, as well as to prime longterm and multi-lifespan design thinking and envisioning $[1,12]$. Friedman and Hendry argue that value alignment can be very overwhelming for designers [12]. Winkler and Spiekermann state that it is challenging to enter the field of VSD because there is still a lack of guidance on "how to accomplish certain tasks" [13]. An initial literature overview of VSD methods with a corresponding indication of the goal is already available and supports projects to get started $[12,14]$.

In an overview study on DSI, Qureshi et al. [15] summarize the status quo of DSI research and discuss their theoretical embedding. However, the internal perspective of DSI projects and their design and development processes are rarely investigated. We seek to open this "black box" and investigate how the selection and adaptation of methods can be supported. For this reason, we draw on the example of a DSI project aimed at developing a digital donation system to understand what must be considered in terms of method selection and adaptation. Through this, we analyze the exemplary multi-layered tasks that can arise within a DSI and which methods can be used while taking into account responsibility and stakeholder values:

\footnotetext{
In this article, we understand methods to be systematic approaches that enable the design and implementation of DSI by producing individual partial results .
} 
Which principles can guide the selection and adaptation of methods in value-sensitive DSI projects?

\section{Related research}

DSI is a relatively new field in IS research [15] and is defined as "a type of social and collaborative innovation in which innovators, users, and communities collaborate using digital technologies to co-create knowledge and solutions for a wide range of social needs [...]." [3] These needs are multi-layered and linked goals that aim to address issues like supporting human rights and gender equality, environmental concerns and climate change, as well as reducing poverty and inequality $[1,2,16]$.

In the design and development, DSI initiatives are confronted with complex tasks $[7,10,11]$. DSI development may benefit from employing multi-layered methods that are typically applied by the IS community when developing digital services $[1,4,5]$, such as usercentric methods like personas ${ }^{2}$ or service blueprints ${ }^{3}$ [5]. Komatsu et al. [5] assembled a toolbox for the development and design of DSI, which shows the diversity of existing methods and extends existing methods with DSI aspects to ensure the social impact. However, a focus on the development of a DSI does not ensure its desired impact or success because values play an important role in developing DSI [11]. For example, a case study conducted among a group of homeless neighbors revealed the need for open discussion about shared values among the actors; neglecting this can lead to the termination of a project [8].

One way of taking human values into account is through VSD. VSD enables DSI initiatives to incorporate relevant contextual factors into the design process. Friedman and Hendry [12] define VSD as follows: "VSD seeks to guide the shape of being with technology. It positions [...] anyone working at the intersection of technology and society to make insightful investigations into technology innovation in ways that foreground the well-being of human beings and the natural world. Specifically, it provides theory, method, and practice to account for human values in a principled and systematic manner throughout the technical design process." The consideration and incorporation of human values are necessary because technologies have an impact on society; in turn, these technologies are to some extent reflections of the underlying values of society, may they be explicitly or implicitly inscribed. Values and technologies reciprocally influence each other [12]. The literature on values and their relation to actions highlights the challenges of dealing with values in application [12]. An important dilemma in this context is that the consequences of the use and adaptation of the DSI cannot be predetermined [11, 12]. A DSI can only attempt to ensure that the context of use is anticipated and included in the design process. DSI teams can choose from a variety of methods, selecting the appropriate methods for their individual contexts. VSD methods can e.g. help to guide through the value election, representation and analysis and prime longterm envisioning [12, 14]. The methods can be categorized according to the following phases: conceptual investigations, empirical investigations and technical investigation [9]. In this study, VSD is executed under the guiding principle of "progress, not perfection" [12]. While resource limitations and technical complexity can impede DSI, VSD methods try to make progress in the DSI area. It is the designers' task to align the innovation with the well-being of people and the environment to ensure that the actions taken during a project are consistent with these overall goals. One way to do this is to have DSI teams engage in debates about their contexts, societies and the corresponding technologies being developed. Through this debates, a well-considered set of criteria for the quality of socially responsive technologies emerges, moving away from perfection to progress with positive societal impact [12].

The selection of methods for arising tasks in the design and development is already considered challenging in the digital innovation field [4]. The multitude of different methods from IS, DSI and VSD, which partly overlap or complement one other, further complicates choice for DSI initiatives. Therefore, this work aims to support DSI initiatives by suggesting design principles (DP) for the selection and adaptation of methods.

\section{Research design}

As described in the introduction, a variety of methods are available for the development of valuesensitive DSI. Based on our analysis of a detailing an ongoing action design research (ADR) project that aims to develop a DSI, we analyze the method selection and adaptation in the ADR project [17]. The ADR project underwent two iterations, illustrated in Figure 1 with

\footnotetext{
2 "Personas are fictional characters who embody the archetype of your customer, beneficiary or financing supporter. They are created through exhaustive observation of the customer segment and the drawing together of their shared characteristics, behaviors, motivations, interests etc." [5].

3 "The Service Blueprint is an operational tool that gives an overview of the organization's operations: key activities, products, services and points of interaction with the intended audience, stakeholders and beneficiaries" [5].
} 


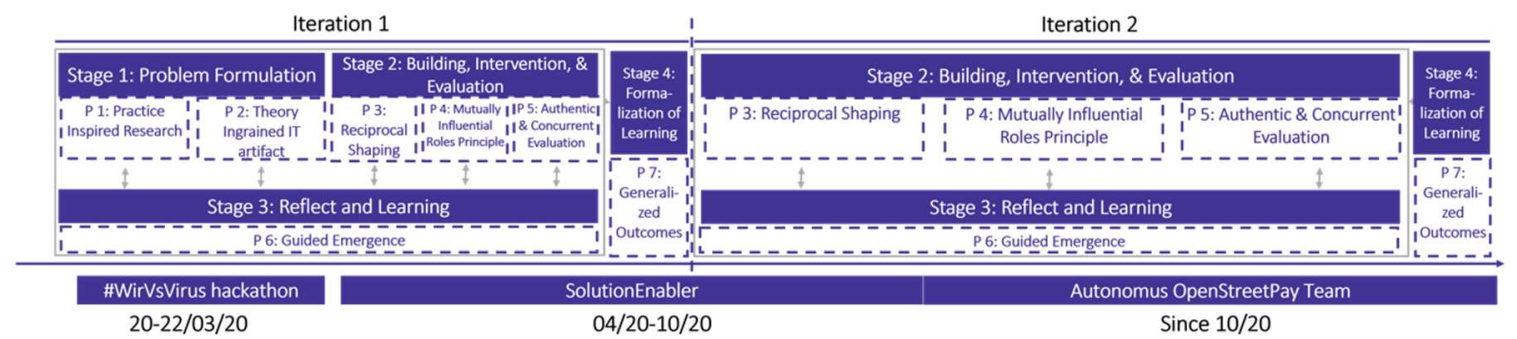

Figure 1. Timetable covering the two design cycles of the ADR project [17]

stages and principles (P). During stage 1 (Problem Formulation) and stage 2 (Building, Intervention, \& Evaluation) of both ADR iterations, method selection took place based on methods from the literature $[5,12$, $14]$ and the experience of project members. Stage 3 (Reflection \& Learning) covered the reflection of how the methods were selected and adapted, especially regarding the methods' relation to values emerging in the digital donation project. In stage 4 (Formulation of Learning), we entailed three levels of conceptual categories, from the specific and unique to the generic and abstract [15]: (1) "generalization of the problem instance" [17] - class of value-sensitive DSI; (2) "generalization of the solution instance" [17] - selection and adaptation of methods from DSI, IS and VSD; and (3) "inductive derivation of design principles from the design research outcomes" [17] - DP for selection and adaptation of methods for value-sensitive DSI.

Table 1 summarizes the DSI, the actors involved, the value proposition and the tools in the project. Furthermore, it outlines the research approach and the data collection. Over the period of 12 months, several concepts and research methods were applied to and included in the design of the digital donation project. In particular, the use of VSD according to Friedman [9] had a great impact on the project. This insight has been used to develop a common understanding of values for the DSI and its ecosystem early in the process [11]. The observations from the DSI project have been recorded and analyzed by creating a "decision log". The log records all decisions made in the project e.g., who receives donations and how. The project team's weekly meeting minutes and the entire document archive served as a basis for reflection and development of the log. In the course of the DSI development, various method toolboxes or existing templates from tools such as miro were used to provide support [5, 12, 14]. However, the team experienced a lack of guidance from in- and outside about which methods to select for which activity in the project. We used the example of the digital donation project to develop a better understanding of the diverse tasks and methods of a value-sensitive DSI.
Figure 2 shows the applied methods (as an exemplary excerpt) with time reference and in relation to the respective research area. Reflecting on the two ADR cycles, the context of the methods was analyzed; if a method was supplemented or questioned with regard to values, it was marked with a (*). Table 3 highlights the selection and adaptation of the relevant methods; these methods served as the basis for the derived DP for the method selection and adaption for value-sensitive DSI (see 4.3).

\section{Results}

\subsection{ADR project description}

The core results of this study are based on the findings of an ADR project dealing with digital donations and payments for homeless people. In the course of the \#WirVsVirus Hackathon in March 2020 initiated by the German Federal Government, the idea was born to help vulnerable groups [10]. The project seeks to address the challenge of taking care of homeless neighbors in a society that reduces the usage of cash by enabling digital donations and digital payments with a new digital service. In our first paper, we investigated the development of a digital donation concept and contributed to research by including a stakeholder and value-oriented perspective to ensure a holistic and sustainable perspective on a DSI [9, 10]. The digital donation concept "includes a digital donation and payment system to enable contactless donations to homeless neighbors. The donation can be made via the donor app or a webpage. The donation receipt and the store payment are processed via a card and the merchantApp. In addition, the concept includes collaboration aspects between homeless neighbors and aid organizations" [10]. The study shows that establishing the DSI is difficult as the project team sought to understand and address existing biases toward homeless neighbors, a vulnerable and marginalized group. An orientation on values was necessary to understand these biases and support the well-being of 
Table 1. Overview of the digital donation ADR project

\begin{tabular}{|l|l|}
\hline $\begin{array}{l}\text { Value } \\
\text { Proposition }\end{array}$ & $\begin{array}{l}\text { Enable digital payment for homeless neighbors without access to digital payment options; donate money via } \\
\text { digital payments to homeless neighbors to make their daily life easier, enable self-responsible care, well-being } \\
\text { and freedom from bias. }\end{array}$ \\
\hline Actors & $\begin{array}{l}\text { Homeless neighbors, homeless aid organizations, donors/citizens, legal entities, social hubs, e-payment } \\
\text { companies, shopping possibilities, project team }\end{array}$ \\
\hline Tools & $\begin{array}{l}\text { SmallChangeCard, SmallChangeApp/webpage, merchantApp, collaboration platforms (Slack, Miro, Google } \\
\text { Drive, Zoom, Git, Figma, Trello), social media platforms (Facebook, Instagram, LinkedIn, Xing), app stores }\end{array}$ \\
\hline $\begin{array}{l}\text { Data } \\
\text { collection } \\
\text { and analysis }\end{array}$ & $\begin{array}{l}\text { Interviews, focus groups, decision log based on weekly protocols of project team, quantitative questionnaire, } \\
\text { reports form homeless neighbors, evaluation of other apps for homeless neighbors, VSD, content from } \\
\text { collaboration boards }\end{array}$ \\
\hline
\end{tabular}

homeless neighbors, as well as to develop a clear orientation for future development of the DSI. For this reason, VSD was involved, and a common understanding of values was elicited in the form of 10 core values (see Table 2) [10]. Furthermore, the study revealed the need for establishing a suitable ecosystem that includes a variety of actors to support the cocreation of the DSI [11]. Based on the experiences from this project, we investigated the integration of the involved actors into the design process of a valuesensitive DSI and its ecosystem [7]. As this project focuses on values, the goals are different than those of typical IS projects that focus primarily on generating economic value. This study addresses the lack of an existing overview of methods indicating which methods can be used for particular tasks related to value-sensitive DSI. Figure 2 shows the six methods selected as examples over the time horizon of the DSI project, as well as where the methods origin from (VSD, DSI/IS, Hybrid). In the project, the methods were selected heuristically for performing the respective necessary tasks. The applied methods differ with respect to their content dimension. The methods of design thinking ${ }^{4}$ and VSD form the overarching frame and apply jointly and interrelatedly to the entire course of the project. This becomes clear in the second iteration, as classic design thinking becomes value-sensitive design thinking. The methods of personas/service blueprint, stakeholder analysis and value-oriented prototyping ${ }^{5}$ were applied during individual steps within the overarching frame. For this purpose, the task-oriented selection of methods (4.2) is described first, followed by an explanation of the DP for selecting and adapting methods (4.3).

\subsection{Task-oriented method selection}

As already described, the tasks in the DSI project were complex due to the high number of stakeholders and their perspectives. In the following, five exemplary tasks of the DSI project are described to outline the scope of the DSI project and which methods have been selected for supporting the activities. To demonstrate the diversity of tasks, the examples selected range from problem definition/idea generation to prototypical implementation. Table 3 shows which tasks were performed (column 2) and which methods (column 3) were selected for supporting these tasks. For each method, we explain why it was chosen for the task (column 4). We then summarize any necessary adaptations of each method, particularly as pertains to values (column 5) if values were not already a part of the method. For each method, the relationship to the values of the DSI is considered to classify the ethical perspective (column 6). The challenges of method selection and adaptation are included in column 7 .

Task no. 1: finding a solution for vulnerable group. The first task is finding a solution for an existing problem. The task includes the determination of the DSI's objective with regard to the protection of the vulnerable user group and their needs/values. But it also needs to take organizational, legal, and technical requirements into account and consider them when building first prototypes. Therefore, we used the method of design thinking as an overarching framework (see Figure 2/Table 3 in green). The design thinking process can be broken down into individual steps, though each discrete stage differs depending on which process template or best practices are being followed. According to the Hasso Plattner Institute, the steps unfold as follows: understand, observe, define point of view, ideate, prototype and test [19]. This step can be seen as a superordinate task and method. For this reason, the following methods describe in which phase of the design thinking process the corresponding tasks occurred. During the hackathon, a first short iteration was already conducted, with the test following the

\footnotetext{
4 "Design thinking is a creative, individual-level process influenced by social-level factors (that is, high inspiration by others, high user-centricity, high prototyping, and low criticism by other), which includes attention, memory, and learning and leads to an aesthetically appealing object" [18]

5 "Development, analysis, and co-design of [...] prototypes [...] to scaffold the investigation of value implications of yet-to-be-build or widely adopted technologies" [12].
} 
Table 2. Values of OpenStreetPay cf. [10]

\begin{tabular}{|l|l|}
\hline$\#$ & Value \\
\hline 1 & Be human. In everything we do: we do it out of humanity and with passion. \\
\hline 2 & Respect dignity. We treat each other, our partners, and each of our homeless neighbors with respect. Without exception. \\
\hline 3 & Reach out. Small amounts of money make everyday life easier for our homeless neighbors. We enable self-responsible care. \\
\hline 5 & $\begin{array}{l}\text { Enable solidarity and individuality. We help with a monthly fixed amount and enable the collection of individual donations. We do not } \\
\text { replace any help. }\end{array}$ \\
\hline 6 & Give perspectives. Nobody should have to live permanently on the street. We try to pave homeless neighbors a sustainable way out of need. \\
\hline 7 & Show transparency. We treat each other fairly and squarely and communicate in this way. \\
\hline 8 & Joined forces. We work together instead of against each other. With partners who share our values. \\
\hline 9 & Be secure. The security of all data of our donors and homeless neighbors is important to us. That's why we protect them. \\
\hline 10 & Take responsibility. We are aware that our donors, partners and, homeless neighbors trust us. We question ourselves and OpenStreetPay. \\
\hline
\end{tabular}

hackathon. Since then, an iterative run of the design thinking has been undertaken. The interviews and acceptance test conducted shortly after the hackathon made clear that there was a need for a discussion of values, as there was recurring discussion about the responsibility of the solution. This led to task no. 2 .

Task no. 2: finding common ground. As a result of the test activities, the DSI team was confronted with the question of the ethical positioning of their DSI, as different stakeholders had different and conflicting needs (e.g., prejudice-free treatment vs. no card for drug addicts). This led to new tasks that had not previously been covered in the design thinking. The DSI team had the task of establishing a common understanding of values based on empirical data from the ecosystem on relevant issues; this was done to avoid recurring discussions. The common understanding was implemented with the help of VSD (see Figure 2/Table 3 in yellow). Since then, VSD has emerged as a framework beyond design thinking and has led to the consideration of values, turning design thinking into value-sensitive design thinking. The empirical investigation (which was covered in the first paper) was carried out on the basis of the empirical results in order to subsequently discuss the conceptual and technical investigation on this basis, as well as to record the 10 core values of the project in a self-designed workshop $[9,10]$. In this context, the definition of values can be seen under the point of view stage of design thinking.

Task no. 3: understanding perspectives of user groups. In order to tailor the solution in the development phase to the different user groups, it was necessary to carry out a value-sensitive elicitation of user requirements, taking into account different perspectives and the diversity of users in the second design thinking run (covering steps understand, observe, point of view and ideate). For this purpose, the user-centric methods, personas and service blueprints were employed at the beginning of the design thinking process [5] (see Figure 2/Table 3 in red).
Task no. 4: developing the prototype of the DSI. As a contribution to problem-solving strategies during the design thinking process, it was the task of the DSI team to develop prototypes over the course of the prototyping step. Throughout the hackathon, this was done without any reference to or guided discussion of values. However, emerging discussions after the hackathon led to the need for explicitly discussing values. The resulting prototypes were implemented with the help of value-oriented prototyping - a method that is already used in the VSD $[12,20]$ (see Figure 2/Table 3 in blue).

Task no. 5: selection of partners and shaping the DSI ecosystem. It became clear that the long-term sustainable anchoring of the DSI in the ecosystem was particularly important, and this was considered in the respective steps by applying the stakeholder analysis method (see Figure 2/Table 3 in orange). This selection task can be categorized as an extended form of design thinking in the steps understand, observe and ideate [21, 22]. Stakeholder analysis was conducted several times and served as the basis for defining the user groups and supporting the selection of partners.

\subsection{DP for selecting and adapting methods for analysis and design value-sensitive DSI}

The process of method selection and adaptation is complex. Selection is often guided by the experience of individuals or conducted heuristically based on participants' knowledge, which was also the case for the ADR project under discussion. By formalizing the learnings of the ADR project, we seek to provide support for the selection and adaptation of methods in future value-sensitive DSI projects. Based on analysis of the tasks and methods that were used to accomplish the selection and adaptation task (4.2), we continued to summarize the formalized learnings. The investigation of the method adaption and selection was concluded with the formation of corresponding DP, which arose 
through repeated discussions among the researchers. In the following sections, we assess the respective methods and their applications to determine the empirical grounding of the DP (cf. Table 3 ).

DP 1: allow autonomy in method selection. DSI often arise in interdisciplinary grassroot spaces [3, 7]. Different methods stemming from different fields are applied and, accordingly, different people bring their own canon of method knowledge with them. These experts in their fields should be given the freedom to apply the methods they need and, if (method) knowledge is still missing, to explicitly search for people who could support the project with their knowledge.

In the digital donation project, the selection of usercentered methods was not conducted based on a formalized decision-making process, as many of the active and former team members in the hackathon have strong user-centered and solution-oriented backgrounds and are familiar with methods like design thinking, personas, service blueprints, prototyping and stakeholder analysis. The inclusion of VSD and related methods was based on findings from the literature and a team member's idea to explicitly consider values.

DP 2: investigate and understand the interrelationships of the methods. Given the multitude of available methods, DSI initiatives should keep track of how the applied methods are connected with one other. This can serve to save time and reduce redundant data from being produced.

For example, Figure 2 presents a first attempt at relating the applied methods to the DSI project. We considered that some methods were used in a superordinate way, while others served to fulfill smaller tasks. However, there remained a lack of overlap among the methods in terms of content. For example, the stakeholder analysis was the basis for personas and service blueprints; whereby, those again contain similar components.

DP 3: select the right point in time for the value discussion (not too early, not too late). The timing of the discussion of values should be chosen carefully. If values are discussed too early, debate on principles could prevent the team from creating an idea and common ground. If values are discussed too late, considerable work might have already been done that would then need to be revised based on underlying values. A discussion of values would also be considered to be happening too late if the project members have already spent significant time participating in unstructured discussions of values.

Based on the experiences of the present ADR project, we found that it was helpful to begin the value discussion after the first results had been achieved; this helps ensure that team members do not get "lost" in fundamental discussions and are able to first develop a common understanding of the problem and potential solutions. When team members noticed that discussions were recurring, they determined this to be the optimal point in the process to discuss values.

DP 4: address the diversity of tasks and responsibilities by selecting different IS, DSI and VSD methods. In addition to the tasks described in 4.2, DSIs require additional tasks. Eliciting a team's values is simply a starting point; the values must then be inscribed in the DSI and its ecosystem, which is done using a variety of methods, as discussed above. However, there is a partial lack of concrete guidance for experts in the VSD field $[13,23]$. Experience from the project has shown that in order to produce results, a mix of methods from IS, DSI and VSD was necessary.

An example of this phenomenon would be a mixed form of stakeholder analysis, which is found in DSI, IS and VSD, aiming to identify stakeholders and understand their needs, values and interests in relation to the project $[12,22]$. Adaptation of this method often occurs in projects to varying degrees.

DP 5: evaluate methods based on their ethical properties. The present project revealed that technologies and methods both reflect stakeholder values. This became particularly clear when using personas. Thus, DSI initiatives should question their methods with regard to their ethical properties.

Directly after the hackathon and before finding the common values, the team started to develop personas for the user groups of donators and homeless neighbors. For this, there were initial approaches to classify users in terms of their personal characteristics, goals and abilities [5, 24]. After the discussion of the values and short development of the personas, it became clear that applying the persona method would bear the risk of capturing and perpetuating existing stereotypes. The danger of inscribing prejudices in the form of personas contradicts the approach of protecting the dignity of every person and thus one of the 10 values of the DSI (see Table 2, \#2) [9, 10]. Personas should only be used if they do not represent fictional characters but are close to an individual with whom a team member has spoken. The method should be adapted accordingly. Through this experience, it became clear that methods also need to be examined in terms of values and that values can conflict with methods. If the method is adapted as described above, it is only tailored to people who are already part of the creation/process. Therefore, it is necessary to revise, update or extend the personas on a regular basis. This can be very time consuming for 


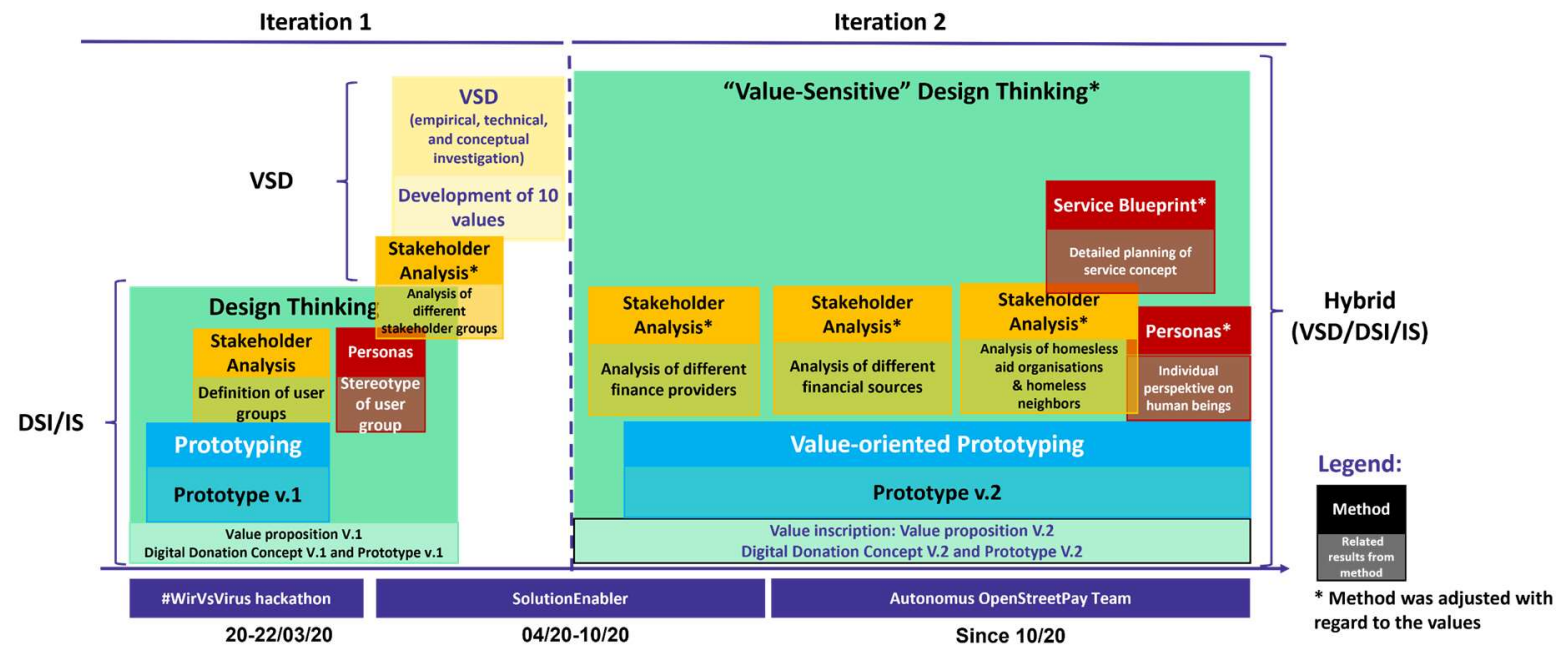

Figure 2. Methods of the value-sensitive ADR project over time

both the DSI team and the stakeholders involved. Service blueprints form a more prejudice-free method in this context, which can be used to support similar design tasks. Here, the DSI service is viewed from the perspective of different user groups [5]; however, less attention is paid to the users individual characteristics and more to their use of the service.

DP 6: integrate values into methods that do not capture any value perspective or choose VSD method alternatives instead. In order to meet the responsibility toward society, it is possible to apply VSD methods and to consider values in the development process or to extend existing methods by including a value perspective [12].

As can be seen in Figure 2, the separate consideration of methods over time has become a hybrid use of DSI, IS and VSD methods. An example from the value-sensitive DSI project is the use of the service blueprint method. From the point of view of the SmallChangeCard owners, for example, considered in which phase they are, at which action, which touchpoint is relevant, which visible actions are performed by the DSI project (frontline) and which invisible actions (backstage) and supporting systems (below ground systems) are running or present during it. As values are inscribed in all elements, the team decided to make the values explicit in order to emphasize those that were most relevant in each phase. For this purpose and for DP 5 , the team developed a test to better understand the emotions, needs and values of the users.

DP 7: open higher-level "method frames" (such as design thinking) for VSD methods and make them value sensitive. When developing a value-sensitive DSI, it is also necessary to extend higher-level methods (here called "method frames") with respect to VSD methods. Furthermore, there are more than one VSD method [12] to be integrated into the method frame (like the design thinking process). Depending on the use case, it is necessary to find out which VSD method is best suited, which excludes the simple integration into design thinking and requires an examination of the methods [23]. This also creates challenges. Design thinking is often a chosen method because of its usercentric and agile design. The integration of VSD could limit the ease and speed of using the method; however, this integration is necessary in favor of the development team's and app's social responsibility and values.

In the DSI project, the relationship of design thinking to values is twofold. On the one hand the hackathon and the subsequent test brought about the discussion on values and on the other hand it was necessary for the team to include VSD methods in every step from the development of the values onwards.

DP 8: repetitively discuss value inscription during intermediate versions of the prototype and challenge core values if necessary. Despite the sacrifices of DP 7, including a discussion of values in favor of responsibility is key. In doing so, it is important for DSI initiatives to understand the significance of actions and design decisions in relation to values [12].

An example of this discussions would be the insights gained from prototyping. Over the course of the hackathon, an initial prototype was developed, about which values had not yet been explicitly discussed. After value identification, the list of values was used as a basis for the revision of the concept and the prototype. Over the course of team meetings, new results - for example in concept, UX design or implementation were assessed on the basis of the list of values. Translating values into requirements can be both unclear 
Table 3. Methods Selection and adaptation for Analysis and Design in Value-Sensitive DSI Projects

\begin{tabular}{|c|c|c|c|c|c|c|}
\hline$>$ & Task & Method & Reason for selection & Need for adaptation & Influence of values (and determination) & Challenges \\
\hline 1 & $\begin{array}{l}\text { Finding a solution for } \\
\text { vulnerable group } \\
\text { Determination of the DSI's } \\
\text { objective with regard to the } \\
\text { protection of the vulnerable user } \\
\text { group and their needs/values, as } \\
\text { well as taking into account } \\
\text { organizational, legal and } \\
\text { technical requirements and } \\
\text { covering it in first prototypes. }\end{array}$ & $\begin{array}{l}\text { Design } \\
\text { thinking [18] }\end{array}$ & $\begin{array}{l}\text { - Team structure } \\
\text { - Incorporation of a } \\
\text { "needs-oriented" } \\
\text { method } \\
\text { - Problem solving is in } \\
\text { the foreground } \\
\text { - Integration of different } \\
\text { stakeholders }\end{array}$ & $\begin{array}{l}\text { - Integration of VSD methods } \\
\text { on each step [10,25] } \\
\text { - Consideration of the } \\
\text { ecosystem and long-term } \\
\text { anchoring }\end{array}$ & $\begin{array}{l}\text { - Brought about discussion of values } \\
\text { - Contains values in every step, just needs to be made } \\
\text { visible }\end{array}$ & $\begin{array}{l}\text { - Variety of VSD methods to } \\
\text { be selected depending on } \\
\text { the case makes integration } \\
\text { difficult } \\
\text { - Ease of design thinking } \\
\text { could be limited or speed of } \\
\text { innovation is reduced, but } \\
\text { in favor of social } \\
\text { responsibility }\end{array}$ \\
\hline 2 & $\begin{array}{l}\text { Finding common ground } \\
\text { Establish a common } \\
\text { understanding of values based on } \\
\text { empirical data from the } \\
\text { ecosystem on relevant issues }\end{array}$ & $\begin{array}{l}\text { VSD - } \\
\text { empirical } \\
\text { technical } \\
\text { and concept- } \\
\text { ual in- } \\
\text { vestigation } \\
{[9]}\end{array}$ & $\begin{array}{l}\text { - Sensitive user group } \\
\text { and sense of } \\
\text { responsibility of the } \\
\text { team } \\
\text { - Repetitive discussions } \\
\text { in the team regarding } \\
\text { value alignment }\end{array}$ & $\begin{array}{l}\text { - Completion of the } \\
\text { investigation with own } \\
\text { target direction } \\
\text { - Own workshop design to } \\
\text { suit purely digital } \\
\text { collaboration }\end{array}$ & - Values were created based on this method & $\begin{array}{l}\text { - Do justice to different } \\
\text { people and groups of people } \\
\text { especially with regard to } \\
\text { value tensions } \\
\text { - Implementation of values } \\
\text { and inscription in DSI and } \\
\text { its ecosystem }\end{array}$ \\
\hline 3 & $\begin{array}{l}\text { Understanding perspectives of } \\
\text { user groups } \\
\text { Value-sensitive elicitation of user } \\
\text { requirements taking into account } \\
\text { different perspectives and } \\
\text { diversity of users }\end{array}$ & $\begin{array}{l}\text { Service } \\
\text { blueprint } \\
\text { and } \\
\text { personas [5] }\end{array}$ & $\begin{array}{l}\text { - Understand relationship } \\
\text { of user groups to DSI } \\
\text { - Designing processes to } \\
\text { suit user groups }\end{array}$ & $\begin{array}{l}\text { - Personas only as a } \\
\text { superordinate user group } \\
\text { - Understanding of } \\
\text { individuals in order not to } \\
\text { perpetuate stereotypes and } \\
\text { prejudices } \\
\text { - Value influence in the } \\
\text { service blueprint }\end{array}$ & $\begin{array}{l}\text { - Personas were started before values and not } \\
\text { continued because of values; a person can only be } \\
\text { seen as a whole } \\
\text { - Recognize possible prejudices against a user group } \\
\text { and actively counteract them by inscribing values } \\
\text { into the DSI } \\
\text { - Values form the service blueprint and need to be } \\
\text { mapped } \\
\text { - Design a method to examine needs, emotions, and } \\
\text { understanding of values in use }\end{array}$ & $\begin{array}{l}\text { - DSI is only tailored to } \\
\text { people who are already part } \\
\text { of the creation/process } \\
\text { - Need for regular revision } \\
\text { - Time consuming for } \\
\text { involved stakeholders }\end{array}$ \\
\hline 4 & $\begin{array}{l}\text { Developing the prototype of the } \\
\text { DSI } \\
\text { Taking the values into account, } \\
\text { the first prototypes of the later } \\
\text { DSI are designed. }\end{array}$ & $\begin{array}{l}\text { Value- } \\
\text { oriented } \\
\text { prototyping } \\
{[12,20]}\end{array}$ & $\begin{array}{l}\text { - Agile development of } \\
\text { relevant content } \\
\text { - Ability to gather } \\
\text { feedback from users } \\
\text { faster }\end{array}$ & $\begin{array}{l}\text { To take note of the values } \\
\text { during development of the } \\
\text { prototype } \\
\text { - Inscription of the values in } \\
\text { the prototypes } \\
\text { - Prototype reflection based } \\
\text { on the values }\end{array}$ & $\begin{array}{l}\text { - Values are inscribed into the prototype } \\
\text { - Values are discussed in the team on the basis of the } \\
\text { mockup after it has been designed. }\end{array}$ & $\begin{array}{l}\text { - Conversion of values into } \\
\text { requirements } \\
\text { - Verifiability of values not } \\
\text { clearly realizable and } \\
\text { dependent on interpretation }\end{array}$ \\
\hline 5 & $\begin{array}{l}\text { Selection of partners and } \\
\text { shaping the DSI ecosystem } \\
\text { Selection of partners and } \\
\text { definition user groups to } \\
\text { establish a DSI ecosystem in } \\
\text { compliance with the DSI values }\end{array}$ & $\begin{array}{l}\text { Stakeholder } \\
\text { Analysis [21, } \\
\text { 22] }\end{array}$ & $\begin{array}{l}\text { - Understanding of the } \\
\text { ecosystem and } \\
\text { stakeholders of the DSI } \\
\text { - Realization of DSI not } \\
\text { possible without } \\
\text { stakeholders }\end{array}$ & $\begin{array}{l}\text { - Mixed variant: Collect } \\
\text { stakeholders and understand } \\
\text { their needs and values. } \\
\text { - Do not make own } \\
\text { assumptions, ask } \\
\text { - Selection of partners driven } \\
\text { by values } \\
\end{array}$ & $\begin{array}{l}\text { - Stakeholders shape the values } \\
\text { - Selection of stakeholders/partners according to } \\
\text { value alignment }\end{array}$ & $\begin{array}{l}\text { - Green- and social-washing } \\
\text { complicate the choice } \\
\text { - Lack of detailed } \\
\text { information } \\
\text { - Takes a lot of time and is } \\
\text { hardly affordable for } \\
\text { volunteer projects }\end{array}$ \\
\hline
\end{tabular}


and challenging, as the translation relies on subjective interpretation [23]. Furthermore, if team members are unable to grasp the meaning of decisions being made in terms of ethical influence, the working process is increasingly difficult. All of this taken together highlights the importance of continual communication of values among a development team.

DP 9: include new tasks for ethical consideration of values into the DSI design process. The previous DP 8 has already indicated this DP. The integration of values into the design process necessitates that DSI initiatives include corresponding tasks in their development process.

During the project, the DP became apparent in various stages. It became clear that working with a sensitive user group requires a high level of responsibility (after the first design thinking iteration, Figure 2) and discussions about values were repeated. The project team decided to conduct a workshop on value understanding [10]. Classic design thinking does not include a consideration of values, as is also the case with many other user-centered methods.

DP 10: include methods for analysis and understanding of the ecosystem for long-term anchoring. DSI are rarely created as a single solution, so the solution under consideration is also created in a DSI ecosystem $[7,10]$. In order to maximize the societal impact, the anchoring in the ecosystem is necessary [7, 15], which must be considered in the canon of methods.

In this DSI, the anchoring was implemented with the help of stakeholder analysis as part of the design thinking approach. Therefore, the stakeholder analysis was used to better understand the ecosystem and define different user groups and co-creating actors.

DP 11: provide an integrated digital tool infrastructure for supporting the use of methods. As DSI often start as grassroots projects, human and time resources are often scarce [26]; effective choice of tools is necessary to maximize resources.

In the DSI project, the selection of tools was based on (cost-free) availability for social projects, integrability with one other, as well as with the available templates. It would save time and avoid inconsistencies, for example, if linked methods (DP 2) could also be developed in an integrated manner and supported by integrated tools. However, we are not yet aware of any tool that makes it possible to link the use of these methods and their results.

DP 12: apply methods according to achieve "progress, not perfection" [12]. Since various methods are available, it is necessary to balance the time spent and the knowledge gained in relation to the applied method. Especially in view of the limited resources of
DSI or grassroots organizations, methods are valuable supports even if they are not utilized to their full extent [26].

Examples of methods used throughout the DSI project include stakeholder analysis and the selection of partners. Lack of information sources and nontransparent communications lead to high efforts for assessing companies. In addition, values have to be broken down into concrete criteria. Green- and socialwashing complicate the selection of methods. It takes a lot of time to get valid data for deciding whether a potential partner complies with the values. For this reason, Friedman and Hendry's statement discussed above is relevant to reiterate here: "progress, not perfection" [12]. DSI initiatives should not be discouraged from applying methods and incorporating values into their projects due to own exceeding expectations.

\section{Discussion and conclusion}

Research on the selection and adaptation of methods for linking DSI, IS and VSD has only recently begun and remains sparse $[5,13]$. In this article, we have shown examples of the tasks that can arise in a valuesensitive DSI project and the methods that can be used to employ them. Based on the experiences from such application, the selection and adaptation of methods for value-sensitive DSI were investigated in order to formalize the learnings as DP. During the process of developing DP, an analysis of the tasks of a valuesensitive DSI and the relevant applied methods informed the development of the DP. We highlighted the challenges related to jointly applying methods from IS, DSI and VSD to help both researchers and practitioners in better understanding the selection and adaptation of methods. Furthermore, the results of the present study point to the need for making this method knowledge accessible and available for DSI initiatives by providing templates in common collaboration tools. In the context of DSI through the lens of VSD, it is important in both research and practice to further investigate methods with regard to their ethical properties.

This study is based on the abstraction of results from a single ADR project. Further methods and tasks should be considered and categorized in the context of different value-oriented projects to further extend the list of DP available for supporting the work of DSIs. This could ultimately lead to a meta-classification of the methods.

Since the young research field of DSI is growing and a multitude of DP are emerging, it would also be 
interesting to examine these DP in detail with regard to their theoretical foundation and to work out the similarities and differences in a meta-study. A first overview study on DSI has already been published and could serve as a starting point [15]. It would be particularly interesting to take a closer look at the different embedding options - for example, with regard to VSD and emancipatory design [27].

\section{References}

[1] Leong, C., F. Tan, and M. Ahuja, "IS for Good-10 years to SDG: Where we have been and where we need to go?", ICIS, 2020, pp. 1-9.

[2] United Nations, Sustainable Development Goals, https://www.un.org/sustainabledevelopment/.

[3] Bria, F., E. Almirall, P. Baeck, H. Halpin, J. Kingsbury, F. Kresin, and others, "Growing a digital social innovation ecosystem for Europe", DSI Final Report. A deliverable of the project "Digital Social Innovation". Brussels: European Commission, DG Connect, 2015, pp. 1-99.

[4] Kumar, V., 101 design methods: A structured approach for driving innovation in your organization, Wiley, Hoboken, NJ, USA, 2013.

[5] Komatsu, T., A. Deserti, and F. Rizzo, Social Innovation Business Toolbox, 2016.

[6] Terstriep, J., D. Rehfeld, and M. Kleverbeck, "Favourable social innovation ecosystem(s)? - An explorative approach", European Planning Studies, 28(5), 2020, pp. 881-905.

[7] Eckhardt, J., C. Kaletka, D. Krüger, K. MaldonadoMariscal, and A.C. Schulz, "Ecosystems of Co-Creation", Frontiers in Sociology, 6, 2021, pp. 1-11.

[8] Whittle, J., M.A. Ferrario, and W. Simm, "CommunityUniversity Research: A Warts and All Account", in Into the Wild: Beyond the Design Research Lab, A. Chamberlain and A. Crabtree, Editors. 2020. Springer International Publishing: Cham.

[9] Friedman, B., Human Values and the Design of Computer Technology, Cambridge University Press, Cambridge, 1997.

[10] Gebken, L., P. Drews, and I. Schirmer, "Stakeholder and Value Orientation in Digital Social Innovation: Designing a Digital Donation Concept to Support Homeless Neighbors", in Proceedings of the 54th HICSS. 2021: Maui.

[11] Gebken, L., C. Kurtz, P. Drews, I. Schirmer, and Böhmann, Tilo, (in press), "Human-Value-Oriented Digital Social Innovation: A Multilevel Design Framework", in Proceedings of 42nd ICIS. 2021: Austin, Texas.

[12] Friedman, B. and D. Hendry, Value sensitive design: Shaping technology with moral imagination, Mit Press, Cambridge, 2019.
[13] Winkler, T. and S. Spiekermann, "Twenty years of value sensitive design: A review of methodological practices in VSD projects", Ethics and Information Technology(23), 2018, pp. 17-21.

[14] Friedman, B., D.G. Hendry, and A. Borning, "A Survey of Value Sensitive Design Methods", Foundations and Trends ${ }^{\circledR}$ in Human-Computer Interaction, 11(2), 2017, pp. 63-125.

[15] Qureshi, I., S.L. Pan, and Y. Zheng, "Digital social innovation: An overview and research framework", Information Systems Journal(31:5), 2021, pp. 647-671.

[16] Eckhardt, J., C. Kaletka, and B. Pelka, "New Initiatives for the Empowerment of People with Activity Limitations An Analysis of 1,005 Cases of (Digital) Social Innovation Worldwide", in Universal Access in Human-Computer Interaction. Methods, Techniques, and Best Practices, M. Antona and C. Stephanidis, Editors. 2016. Springer International Publishing: Cham.

[17] Sein, M.K., O. Henfridsson, S. Purao, M. Rossi, and R. Lindgren, "Action Design Research", MISQ, 35(1), 2011, pp. 37-56.

[18] Meinel, C., L. Leifer, and H. Plattner, Design thinking: Understand - improve - apply, Springer, Berlin, 2011.

[19] Plattner, H., C. Meinel, and L. Leifer, eds., Design Thinking Research: Studying Co-Creation in Practice, 1st edn., Springer-Verlag, 2012.

[20] Woelfer, J.P. and D.G. Hendry, "Stabilizing homeless young people with information and place", Journal of the American Society for Information Science and Technology, 60(11), 2009, pp. 2300-2312.

[21] Nathan, L.P., B. Friedman, P. Klasnja, S.K. Kane, and J.K. Miller, "Envisioning systemic effects on persons and society throughout interactive system design", in 7th ACM Conference on Designing Interactive Systems, G. Marsden, Editor, Cape Town, South Africa. 2008. Curran.

[22] A Guide to the Project Management Body of Knowledge (PMBOK®Guide), 2017.

[23] Friedman, B., M. Harbers, D.G. Hendry, J. van den Hoven, C. Jonker, and N. Logler, "Eight grand challenges for value sensitive design from the 2016 Lorentz workshop", Ethics and Information Technology(23), 2021, pp. 1-12.

[24] Cooper, A., The inmates are running the asylum: Why high-tech products drive us crazy and how to restore the sanity, 2nd edn., Indianapolis, 2004.

[25] Sjøkvist, N.M. and M. Kjørstad, "Eliciting Human Values by Applying Design Thinking Techniques in Systems Engineering", INCOSE International Symposium, 29(1), 2019, pp. 478-499.

[26] Eckhardt, J., C. Kaletka, and B. Pelka, "Inclusion Through Digital Social Innovations: Modelling an Ecosystem of Drivers and Barriers", in Universal Access in Human- 